CPE

1,1

Received 31 July 2018 Accepted 31 July 2018

\section{Supply-side structural reform and the transformational development of China's foreign trade}

\author{
Erzhen Zhang \\ School of Economics, Nanjing University, Nanjing, China, and \\ Xiang Dai \\ Nanjing Audit University, Nanjing, China
}

\begin{abstract}
Purpose - From the perspective of supply-side structural reform, the purpose of this paper is to analyze and discuss the necessity and feasibility of China's foreign trade transformation and development and explores the realization path accordingly.

Design/methodology/approach - This paper mainly uses the speculative method of qualitative research to find out the scientific countermeasures of foreign trade transformation from the supply-side reform level on the basis of in-depth interpretation of the supply-side structural reform and foreign trade transformation and development.

Findings - The study found that the main problem facing China's foreign trade development is structural problems. Therefore, through structural reforms such as technological innovation and institutional innovation, it can effectively promote the transformation and development of foreign trade.

Originality/value - This paper is the original result of the author. Except for the content already quoted in the text, this paper does not contain any other individuals or groups that have published or written the work. Keywords Foreign trade, Supply-side, Structural reform, Transformational development

Paper type Research paper

\section{Questions}

Opening up makes China stronger and it is the inevitable path to prosperity. This was put forward clearly in the report of the 19th CPC National Congress that we must "promote a new pattern of all-round opening up." General secretary Xi Jinping has emphasized that "China's door of opening up will not be closed and will only open wider." This is a major strategy made by the Party Central Committee with President Xi Jinping as the core, based on the accurate judgment of new changes in the international situation and a strong grasp of the development of China's open economy entering a new era at this time. The essence of forming a new pattern of all-round opening up is to transform the open development, namely, to develop a high-level open economy. As one of the important parts of the open economy, China's foreign trade is of decisive significance. It is a pivotal manifestation and the result of entering the international division system, which is dominated by the current global value chain. Owing to its rapid growth, China's foreign trade has been ranked as one of the best in the world. Faced with international and domestic challenges, especially the "anti-globalization" of some advanced economies in the form of trade protection, China's foreign trade development has shifted from high-speed growth to a new stage of high-quality development. We must "transform the driver and improve the quality" as soon as possible. To achieve this goal effectively, China must adopt a supply-side structural reform of foreign trade.

(C) Guizhou Social Sciences. Published in China Political Economy. Published by Emerald Publishing Limited. This article is published under the Creative Commons Attribution (CC BY 4.0) licence. Anyone may reproduce, distribute, translate and create derivative works of this article (for both commercial and noncommercial purposes), subject to full attribution to the original publication and authors. The full terms of this licence may be seen at http://creativecommons.org/licences/by/4.0/legalcode. Originally published in

Simplified Chinese in Guizhou Social Sciences.
\end{abstract}

China Political Economy Vol. 1 No. 1, 2018 pp. $120-129$ Emerald Publishing Limited 2516-1652 DOI 10.1108/CPE-09-2018-002 


\section{The necessity of supply-side structural reform of foreign trade}

First, factors constraining the growth of China's exports exist both on the demand-side and the supply side, but the central aspect of the contradiction is still the latter one. It is difficult for supply side structure and quality level to meet the demands of the international market. This helps to explain recent Chinese consumers' craze for overseas shopping and overseas procurement services. From Japanese toilet lids and rice cookers to New Zealand milk powder and Dutch razors, the Chinese purchase a vast amount of various foreign products. The products produced by domestic companies, whether in terms of quality or brand, cannot meet the "hierarchy of needs" of domestic consumers, let alone be exported to compete in the international market.

In the previous round of open economy development, China seized vital opportunities brought by the development of economic globalization and achieved rapid development of foreign trade through its deep integration into the global value chain. In particular, China promoted the import and export trade relying on processing trade. However, it is undeniable that the previous round of development could be termed as "low-end embedded" and "large but short flow model." "Low-end embedded" is mainly reflected in the fact that China's main production and exports are mostly concentrated in labor-intensive products. While a large number of China's machinery and electronics are more differentiated, more complicated, and even considered to be highly technical and highly competitive, they are actually produced through various forms of processing and assembly for re-export. China is still developing the low-end segment of high-end industries. For example, photovoltaic products were representative products in conventional Chinese foreign exports, but their core technologies and high value-added sectors have not been "absorbed" by China. A "large but short flow model" means that when China integrates into the division system of value chain, the domestic value chain is short. The specialized chain that is undertaken by China is not able to effectively extend to both sides, the value-added ratio in the value chain is low, and its leading role and spillover effects on other industries are limited. In conclusion, from the supply perspective, China's foreign trade development has not completely formed the comprehensive competitive advantages with technology, brand, standards, quality and service as the core; it has not been able to take the lead in completing self-adjustment against the background of "profound readjustment of global economy;" it has not resolved inefficient and low-end supply in a timely and effective manner; and it has not created an "effective and high-end supply" in line with the new trend of global economic development. Therefore, it is imperative to promote the structural reform of the supply side in China's foreign trade.

Second, the current sluggish growth in foreign trade is mainly because of structure. Objectively speaking, the sluggish growth or even negative trend in foreign trade is not a unique phenomenon in China but a "common problem" in global trade in recent years. Foreign trade refers to trade among various countries or regions, so obviously, the foreign trade issue should be considered more objectively and comprehensively in the global context. Generally speaking, there are two kinds of factors that affect the growth rate of trade. One is a short-term factor, which is called cyclical factor or macroscopic factor by the academic circle. The other one is the long-term factor, also known as structural factors in the academia. As a matter of fact, both cyclical factors and structural factors have a profound effect on the slowdown of China's trade to some extent.

The development of trade derives from the expansion of the division of labor, and the evolution of it depends on the trend and pattern of the industry development. That is to say, in the long run, the supply-side structure is certainly the determinant of the division of labor and the trade. Today, the "re-industrialization" strategy is implemented by major countries in the world. They are not just repeating the old pattern of traditional manufacturing industry development, but seeking a new status in the global division of
Supply-side structural reform 
CPE 1,1

labor from the supply-side structural changes and occupying the commanding heights in global industrial chain, taking the lead in "getting out of the dilemma" and becoming a pacemaker in the next round of growth in global trade. This is both a pressure and also an impetus for China to promote the supply-side structural reform and the transformational development of foreign trade.

Third, to maintain a steady medium- to long-term growth in foreign trade, China can only look for solutions from the supply-side structural reforms. The difference between foreign trade and domestic trade is that the demand-side of foreign trade is in the international market, while the demand-side of domestic trade is in the domestic market. Compared to domestic trade, the demand-side factor of foreign trade cannot be regulated by one country. That is why in numerous theoretical and empirical studies the export demand is always regarded as an income function of the international market but not affected by domestic income levels. Since it is impossible to regulate the international market with demand-expanding policies, the only way to maintain the steady development of foreign trade lies in the efforts made on the supply side. More exactly, as the demand-side of foreign trade lies in global market, supply-side structural reform becomes more necessary.

At present, the global economy is undergoing a period of changes and the situation remains complex and severe. While it has become a consensus that the main issue is contradiction of structure, cyclical contradiction still exists and plays an important role in global economic development. In other words, the global economy is in a period of in-depth adjustment in which both cyclical and structural contradictions coexist. In this special period, the traditional demand in the international market is unlikely to rebound sharply in a short term. This poses a serious challenge to China, which has a high level of export-oriented economic development. If we still stick to the conventional foreign trade development model and provide products needed by the traditional demand, we will likely not only face with ever-smaller room to grow, but also larger scale variations which are caused by competition from other developing countries and regions. Notably, the transformational development of foreign trade must be realized in a certain process of growth. If China cannot stabilize its growth rate, the transformational upgrade will lose its supporting conditions. Furthermore, under the division system of the current global value chain, when a country is unable to stabilize the growth rate of foreign trade, it essentially means that this country is losing its ability to integrate into the global value chain further. Obviously, in this sense, since the demands of the international market cannot be regulated, it is of great strategic importance to stabilize foreign trade development by promoting supply-side structural reform, producing marketable and high-quality products, as well as seeking and even leading new demand in the international market.

\section{The connotation of supply-side structural reforms in foreign trade}

To smoothly advance supply-side structural reform of foreign trade, we need to understand the necessity and urgency and also grasp its scientific connotation. The supply-side structural reform of foreign trade actually means the implementation and application of supply-side structural reforms in the field of foreign trade. Therefore, in addition to the general meaning of supply-side structural reforms, it also incorporates the factors of foreign trade. That is to say, this concept not only includes what to supply to the international market, but also how to supply.

As is known to all, over the 40 years since China's reform and opening up, China has become the world's largest trader, as well as the world's largest exporter. However, on overall, China is still at the medium-and-low end of the global value chain, and its comparative advantages are mainly concentrated on the labor-intensive products or the medium-and-low end links in high-end industries. Chinese industries are still characterized by extensive development. The rapid growth of trade driven by extensive development 
features is the result of the full and effective use of its own comparative advantages. Meanwhile, China also benefits from the high international market demand created by the former phase of global economic prosperity. As some scholars have pointed out, making full use of the low-end domestic elements in the international demand market is the essence of promoting the rapid growth of the former round of foreign trade. This long-term extensive development model, having brought certain economic development benefits, has been criticized for both its elements of low added value and low profitability. Driven by this powerful inertia, the long-term extensive development model led to a general manufacturing industry with the reputation of "the world factory." But, it is easy to cause serious overcapacity, especially in the global economic profound adjustment period in which cyclical and structural contradictions coexist. This would cause foreign trade companies with low-profit margins to face challenges and risks of falling profitability and rising debts. The inevitable result is the lack of growth drive and a slowdown in foreign trade growth. This is precisely the current plight of China's foreign trade development. Therefore, the essence of supply-side structural reform is to change the extensive development model through reforms and to transform the factors-driven and investments-driven development to the innovation-driven model. By doing this, we can improve the quality and efficiency of the foreign trade development, enhance the long-term innovation vitality and focus on the long-term and sustainable development of foreign trade. In summary, reducing "low-end and inefficient supply" and increasing "high-end and efficient supply" is one of the important connotations of the supply-side structural reform of foreign trade. That is to say, we must adopt structural reform focused on supply. This point focuses on foreign trade production area.

The supply-side structural reform of foreign trade can take place in the production sector, and from the purely "foreign trade" perspective, it can also take place in the logistics sector. To put it another way, it is changing the supply mode through the reform, specifically, the renovation and innovation in the supply structure. The new motivation for foreign trade growth depends on not only what is supplied but also how it is supplied. High-end and effective supply is significant for opening up and entering the new international market. However, how to do this will largely determine whether it can "cater" for the demands of the international market or not. According to the Heterogeneous Corporate Trade Theory, compared with domestic companies, export-oriented companies tend to have higher survival rates and stronger financing capacity because entering the international market requires more sunk costs. That means small- and medium-sized foreign trade companies are often limited by factors such as capital, technology and their own size. These reasons make it difficult for them to enter the international market. This point has also been confirmed in many theoretical and empirical studies. In a country's export trade, large- and medium-sized enterprises with a small proportion often occupy most of the trade volume while the rankings of small- and medium-sized enterprises in foreign trade are not high (Fernandes et al., 2015). This is normal in the traditional trade pattern. However, with the rapid development of information and communication technology, especially the rapid development and popularization of the internet technology, the above situation is quietly changing. From the perspective of consumers' demand, the importance of personalized and decentralized demand in the international market is increasingly prominent. Besides, the falling costs of entering the international market for small- and medium-sized foreign trade enterprises makes it easier to meet the personalized and decentralized demand in the international market. Undoubtedly, these two factors have provided new kinetic energy for the development of foreign trade. However, the application of these two favorable factors to the real trade depends on the reform and innovation on the structure of foreign trade supply, which can promote the development of foreign trade with new-style trade type. All in all, it is also the important connotations of the supply-side structural reform of foreign trade that
Supply-side structural reform 
CPE 1,1

develop new-style trade types and diversify the structure of foreign trade supply mode while consolidating the traditional import and export pattern at the same time. This point focuses on foreign trade circulation area.

It should be noted that although the supply-side structural reform of foreign trade has a well-established theoretical basis, which mainly originated from the supply schools of the western economics circle, the current supply-side structural reforms for China's foreign trade development are by no means simply following up and copying the existing western economic theories. Even if western supply theory has been developed over a long time, from the neoclassical theory with the core of Say's Law to the new supply economics focusing on traditional supply economics, it cannot be fully applied to China's practice in foreign trade development. The school of supply theory suggests to generally stimulate the input of factors of production via policies such as tax cuts to maintain growth, while the current supply-side structural reform of China and its practice and application in foreign trade is to adjust the structure based on the specific features such as production layout, industry nature, production efficiency and international market demand. That is why it is called supply-side structural reform, not supply-side reform. A report "Seven Questions for the Supply-Side Structural Reform” (Gong et al., 2016a), posted by the People's Daily states that the Party Central Committee with Xi Jinping as General Secretary has comprehensively analyzed the long-term cycle of the world economy, the stage characteristics of China's development and the interaction between them. With its result from the wisdom of the whole party and people, the idea of supply-side structural reform has been put forward from theory to practice. In this way, the reform is a comprehensively integrated innovation based on China's practice and bears Chinese characteristics (Gong et al., 2016b). In the field of foreign trade, the basic starting point is to improve the quality of services and products. To improve the ability of sustainable development in foreign trade, China must implement effective reforms to eliminate the inappropriate configuration of production factors, expand the supply of high-end products and services during the structural adjustment, as well as satisfy changes of international market demand, including the content and methods of consumer demand. That is the essential connotation of the supply-side structural reform.

\section{The goal of the supply-side structural reform in foreign trade}

Speeding up the transformation and development of China's foreign trade is one of the crucial goals of advancing the supply-side structural reform in China's foreign trade. Based on the practice of China's foreign trade development and the actual needs of the transformational development, the goals of the supply-side structural reform of foreign trade, specifically, can be summarized as the following four aspects:

(1) Improving products' quality: when deeply integrated and participating in the division of global value chain dominated by multinational corporations in developed countries, China's manufacturing industry has developed rapidly, narrowing the technological gap with developed countries in general manufacturing industry and becoming a strong country of large-scale manufacturing. However, quantity can never replace quality. Compared with Germany, the USA, Japan and other manufacturing powerhouses, China still has a long way to go. Although China can produce whatever other industrial powers can, the quality of Chinese products simply cannot be compared in terms of manufacturing quality. The Institute of Industrial Economics of CASS recently conducted a survey on the international competitiveness of China's manufacturing industry, aiming to know clearly how big the gap is between China's manufactured products and those of advanced economies (Zhang, 2014). The comparison shows that the selected Chinese manufactured products are highly competitive on the whole. However, in the production process of 
the whole machine, many core parts and components have to be imported. Even in the simplest production links and phases, the quality and details of Chinese products are a far cry from those of developed countries, especially from the industrial powers. According to some researches, the rapid expansion of China's export scale of finished products has not methodically promoted the quality of export products, but has led it to a continuous downward trend ( $\mathrm{Li}$ et al., 2014). Therefore, one of the vital goals of the supply-side structural reform of foreign trade is to upgrade products' quality and refinement levels, so as to transform the low-end supply to high-end supply.

(2) Elevating its status in the value chain: since the 1980s and 1990s, the international division system has been increasingly refined, and the specialized division of labor based on the global value chain has gradually become the dominant form worldwide. The rapid development of China's foreign trade is the result of participation in the division network of the value chain with various forms of processing trade. In the division model of the global value chain, because of different characteristics of factor concentration in different links and stages, there are differences in profitability and additional value creating ability in specialized specific links, namely, the differences in status in division model of the global value chain. The academic circle usually uses the "smiling curve" to describe the division of global value chain. Processing, assembly and manufacturing are the links of low added value, located at the bottom of the curve. Countries and regions specialized in these stages and links apparently have lower levels and capacity on profitability when they take part in division and trade, while technology, R\&D, marketing and after sales are links of high added value on both ends of the "smiling curve. Countries and regions specialized in these stages and links have stronger capacity on profitability and higher levels in the global value chain. Objectively, the essence of China's foreign trade is actually to take part in the global value chain and specialized in the links and stages of low added value such as assembly, processing and simple manufacturing, so China is at the mid-low end of the global value chain. In academic words, this is called "low-end embedded." When facing the profound changes in the current domestic and international environment, especially in the period that the cyclical and structural contradictions coexist and develop, we must elevate our status in the global value chain through supply-side structural reforms. Moreover, with the division in global value chain, the participation of a company or an industry is not only in order to obtain the trade in tasks, but more importantly, from a dynamic point of view, to obtain added value and the ability of elevating status in the chain.

(3) Optimizing the industrial structure: one of the momentous contents and directions of "rebalancing the economy (adjusting the structure and transform motives)" is to optimize and upgrade the industrial structure because the development of industry is the cornerstone of the development of foreign trade. After years of development as an open economy, China has made great strides in "improving" the industries. This can be seen that at the earlier stages, China has simply followed the development path of western developed countries. By actively accepting the technological transfer and diffusion from developed countries, China has developed rapidly in the general manufacturing industry, and even improved technology in the general manufacturing industry. But at the same time, we have to admit that in the high-end and advanced manufacturing industry, China is far behind the world's manufacturing powers in terms of quality and technological innovation. Therefore, after "improving" its industries, China must begin the development at the 
CPE 1,1

new stage of "strengthening" our industries to elevate our status. To realize this goal, China must improve the developing level of advancing and high-end manufacturing industry, transforming from a great power of quantity manufacturing to that of quality manufacturing. This is the optimization and upgrading of the internal structure within the manufacturing industry. In addition, a prominent feature of the current economic globalization is that the trend of service industry globalization has become increasingly evident, which is just like the manufacturing industry globalization. The level of development of service industry and trade has become an important indicator, which can show a country's or a region's ability of taking part in the global competition. However, the former development of foreign trade was mainly focused on the manufacturing sector, developing the trade and the industries by opening up in the field of manufacturing. On the other hand, China's service industry, especially the modern productive service, is lagging behind that of developed countries. To a certain extent, the development of the advanced manufacturing industry must be supported and guided by advanced productive services. Therefore, to optimize and upgrade the industrial structure, we must also promote the development of the modern service industry, especially the advanced productive service industry. This is the optimization and upgrading of the inter-industry structure. That is one of the great goals of supply-side structural reform of foreign trade from the perspective of industrial structure.

(4) Diversifying supply methods: in the traditional product supply mode, China satisfies the global market demand by export and satisfies the consumer country's market demand with FDI. However, neither exports nor FDI is "large scale." In the comparative analysis of the characteristics in international trade and domestic trade, the "large volume" of a single order is often considered as one of the important characteristics of international trade. This is also the practical need to achieve "economy of scale" under the traditional pattern. However, with the continuous advancement of technique such as applied information technology and physical network systems, the traditional "scale-style" supply may experience complete disruption. This is because consumer demand will become increasingly decentralized and individualized. Of course, it does not mean that the pattern of large-scale supply in foreign trade is no longer vital, but it means that the model of supply in the future must be large scale, decentralized and individualized as well. Large-scale supply is still a crucial means for ensuring low cost, but from the perspective of consumer demand, we have to seize new growth points of consumer demand to satisfy the needs of "decentralization and individualization." In the case of ensuring that the total volume has a scale effect, on the consumers' demand for decentralization and individualization, China must combine the large scale, decentralized and individualized supply modes through dynamic configuration of modular supply. By doing this, China can transform their supply mode from focusing on single large orders to dealing with many individualized, decentralized and integrated orders. Consequently, from the perspective of the supply mode, to meet or even lead the trend of international consumer demand, China must implement a supply-side structural reform of foreign trade, change the traditional supply model, create more trading forms and diversify supply patterns.

\section{The measures for the supply-side structural reform of foreign trade}

The key to successfully promote the transformation and development of China's foreign trade lies in the implementation of effective measures for the supply-side structural reform 
of foreign trade. Basically, the supply-side structural reform of foreign trade includes the adjustments on the supply content as well as the supply mode and structure. Based on this realistic demand, China should focus on the following aspects in the supply-side structural reform of foreign trade:

(1) Paying attention to technological innovation: no matter what we do, to improve the quality of products by focusing on the original product areas, to elevate its status in the global value chain, or to adjust and optimize the industrial structure, the most fundamental, direct and efficient method is to upgrade technology. At present, Chinese companies do not have their own core technologies in most industry sectors due to fund shortages and limited intensity of technological transformation, which causes a serious lack of intellectual property and brands. In this connection, China must increase its funding in R\&D and technological transformation to improve its technology. Improving technology is not only an important measure and direct path to promote the upgrading of the industrial structure, but also the only way, on which China can reform the traditional labor-intensive industries with applicable technology and high-tech to sharpen its competitive edge. Of course, with regard to technological innovation and advancement, the government cannot replace enterprises, or decide the allocation of projects or resources. Instead, it must let the market play a decisive role in the allocation of resources, reducing the use of outdated capacity through market competition and producing competitive new products and services. During this process, a powerful government should work on the transformation of services. Namely, the government should remove all barriers to institutional and ideological innovation, rewarding researchers with an adequate benefit compensation, making technology R\&D meet the demand of economic development, making innovation achievements meet the development of the industry, and making innovative projects be transformed to productivity. In that case, technology, knowledge, labor, information, management, capital efficiency and profitability can be upgraded. China boasts a wealth of science and education, with solid foundation in rich resources for science and education to provide the necessary support to technological innovation. It is believed that as long as the reform measures are conducted properly, enterprises or individuals, acting as the economic units, can become real innovators. With the potential for social innovation and vitality, economic units can play an important role in enhancing technology's effect on the transformation of foreign trade during the reform of technological innovation.

(2) Paying attention to craftsmanship: as mentioned above, one of the important directions for the transformation of foreign trade is to consolidate the advantages of the traditional development model. In other words, China should rely on the improvement of quality and refinement, specializing, perfecting and fully knowing its traditional industries. At present, from the perspective of supply and demand, it is more than a problem of excess products but a structural imbalance of products. Specifically, the supply of low-end products is greater than its demand, while the supply of high-end products is significantly insufficient. The supply-side structural reform of foreign trade is to open up the international market and meet the medium-and-high end demand. We can steadily develop by occupying the high-end market. According to the existing international experience, the production of highquality products needs to rely on the craftsmanship. Craftsmanship is a reason why some countries can become industrial powers, such as Germany and Japan. In the 2016 government work report of China, "craftsmanship" was mentioned for the first time. For improving foreign trade products and services, undoubtedly, vigorously advocating craftsmanship is an effective way to promote the supply-side structural
Supply-side structural reform 
$\mathrm{CPE}$ 1,1

reform of foreign trade. Basically, the supply-side structural reform of foreign trade is to improve the quality and production efficiency of foreign trade products and service supply system. Attention to details, be patient and focused, and pursuiting of excellence is the essence of this spirit. Just as the "People's Daily" stated (Li, 2016): while not every person of craftsmanship is an entrepreneur, most successful entrepreneurs are of this good spirit, which represents the spirit of an era and the attitude of firmness, diligence and perfectionism. It can thus be seen that the craftsmanship is closely related to the supply-side structural reform in foreign trade. It is a pivotal path for China's foreign trade transformation based on the supply-side structural reform of foreign trade to improve the quality and profitability of products, and to increase the supply of differentiated as well as high-end products and services with the spirit of craftsmanship. So China should pay attention to cultivating craftsmanship.

(3) Paying attention to institutional innovation: there is no doubt that technological innovation and craftsmanship are the most straightforward and effective measures to promote the transformation of foreign trade, but these measures should not be just publicized. More importantly, the appropriate institution is the prerequisite of inducing these measures. After all, the lack of the impetus and the vitality of technological innovation as well as the lack of spirit of craftsmanship actually comes from the constraints of institutional mechanism. Therefore, it is necessary to create an institutional mechanism that is more suitable or more conducive for innovation. As some scholars have pointed out, the lack of technological innovation capability of Chinese enterprises is indeed a prominent challenge. However, it is the institution rather than the lack of innovation that constrains the technology. To put it another way, Chinese enterprises have inadequate technology and ability for innovation mostly because the institutional mechanism does not stimulate innovation effectively. A good institution can make resources flow to new areas and industries of innovation. In recent years, academics and government departments have become increasingly aware of the valuable spirit of craftsmanship of industrial powers such as Germany and Japan. We have talked about their attitudes of excellence, and how well entrepreneurs with craftsmanship can adhere. However, in fact, it is the institutional logic behind their craftsmanship that deserves to be studied. In-depth institutional reasons such as lifelong employment, powerful labor unions, effective intellectual property protection and corporate governance systems are the foundation and cultural background for the formation of excellent craftsmanship. Thus, besides technology, China also needs institutional reform and innovation. In terms of institutional improvement, there are three things that should be focused on in the reform ahead: solid intellectual property protection, an efficient foreign trade management system and more open fields. Solid intellectual property protection is the most important institutional guarantee for aggregating global innovation factors and inspiring enterprises to innovate; an efficient foreign trade management system is a further requirement for the facilitation of trade and investment as well as the evolution of the global division of labor; the expansion of the open industries is essential to expand market access, including the opening up of high-end manufacturing and service industries, so that a variety of better products and services can be created in an environment with more competition.

(4) Paying attention to model innovation: China's supply mode of products and services should also urgently seek innovation. The progress of technology and the cultivation of craftsmanship are variables that change slowly, while the innovation of foreign trade management model is a variable that can change rapidly. This has long-term 
effects on industries and can create new momentum for foreign trade growth. Under the tremendous pressure of the slowdown in the growth of foreign trade, the innovation of foreign trade management model can stabilize the foreign trade growth effectively. So far, this point of view has been proved by certain new trade industries. Some new business models such as market procurement, cross-border e-commerce and overseas warehousing have achieved initial success. The Chinese Government should strongly support the innovation of these new trade industries. For cross-border e-commerce, the regulatory model of inspection, quarantine, declaration and release of products should be built. Also, the government should research new policies on the management model of custom clearance that are appropriate to this new trade industry. For market procurement, there have been some experimental regions in China. If everything goes well, the pilot projects will be expanded and the successful experience will be popularized. In promoting the development of foreign trade comprehensive service enterprises, it is necessary to formulate pilot programs as soon as possible and introduce policies and measures to support the development of these enterprises.

\section{References}

Fernandes, A., Freund, C. and Pierola, M. (2015), "Exporter behavior, country size and stage of development: evidence from the exporter dynamics database", Journal of Development Economics, Vol. 119, pp. 121-137.

Gong, W., Xu, Z. and Wang, K. (2016a), "Seven questions for supply-side structural reform”, People's Daily, January 4, p. 2.

Gong, W., Xu, Z. and Wang, K. (2016b), "Seven questions for supply-side structural reform: authoritative experts' opinion on China's current economy", Journal of Socialist Theory Guide, Vol. 1, pp. 4-10.

Li, H. (2016), "See craftsmanship from Ms. Dong (Dong Mingzhu)'s Feast”, People’s Daily, November 3, p. 5.

Li, K., Jiang, W. and Song, L. (2014), "The mystery of changes on China's export products' quality: microscopic interpretation based on market access", Social Sciences in China Press, Vol. 3, pp. 80-103.

Zhang, E. (2014), “China's foreign trade transformation: processing trade, 'smiling curve' and industrial choices", Contemporary Economic Research, Vol. 7, pp. 14-18.

\section{About the authors}

Erzhen Zhang is Professor of Economics at Nanjing University. His principal research interest is the theory and practice of the open economy. Erzhen Zhang is the corresponding author and can be contacted at: zrz@nju.edu.cn

Xiang Dai is Professor at the Government Auditing Institute of Nanjing Audit University. His main research areas are open economic theory and practice, global value chain and China's industrial development.

For instructions on how to order reprints of this article, please visit our website: 